Marquette University

e-Publications@Marquette

$1-1-2007$

\title{
Hexabenzo[4.4.4]propellane: A Helical Molecular Platform for the Construction of Electroactive Materials
}

Paromita Debroy

Marquette University

Sergey V.Lindeman

Marquette University, sergey.lindeman@marquette.edu

Rajendra Rathore

Marquette University

Accepted version. Organic Letters, Vol. 9, No. 21 (2007): 4091-4094. DOI. (C) 2007 American Chemical Society. Used with permission. 
Marquette University

e-Publications@Marquette

\title{
Chemistry Faculty Research and Publications/College of Arts and Sciences
}

This paper is NOT THE PUBLISHED VERSION; but the author's final, peer-reviewed manuscript. The published version may be accessed by following the link in the citation below.

Organic Letters, Vol. 9, No. 21 (2007): 4091-4094. DOI. This article is (C) American Chemical Society and permission has been granted for this version to appear in e-Publications@Marquette. American Chemical Society does not grant permission for this article to be further copied/distributed or hosted elsewhere without the express permission from American Chemical Society.

\section{Hexabenzo[4.4.4]propellane: A Helical Molecular Platform for the Construction of Electroactive Materials}

\author{
Paromita Debroy \\ Department of Chemistry, Marquette University, P.O. Box 1881, Milwaukee, WI \\ Sergey V. Lindeman \\ Department of Chemistry, Marquette University, P.O. Box 1881, Milwaukee, WI \\ Rajendra Rathore \\ Department of Chemistry, Marquette University, P.O. Box 1881, Milwaukee, WI
}



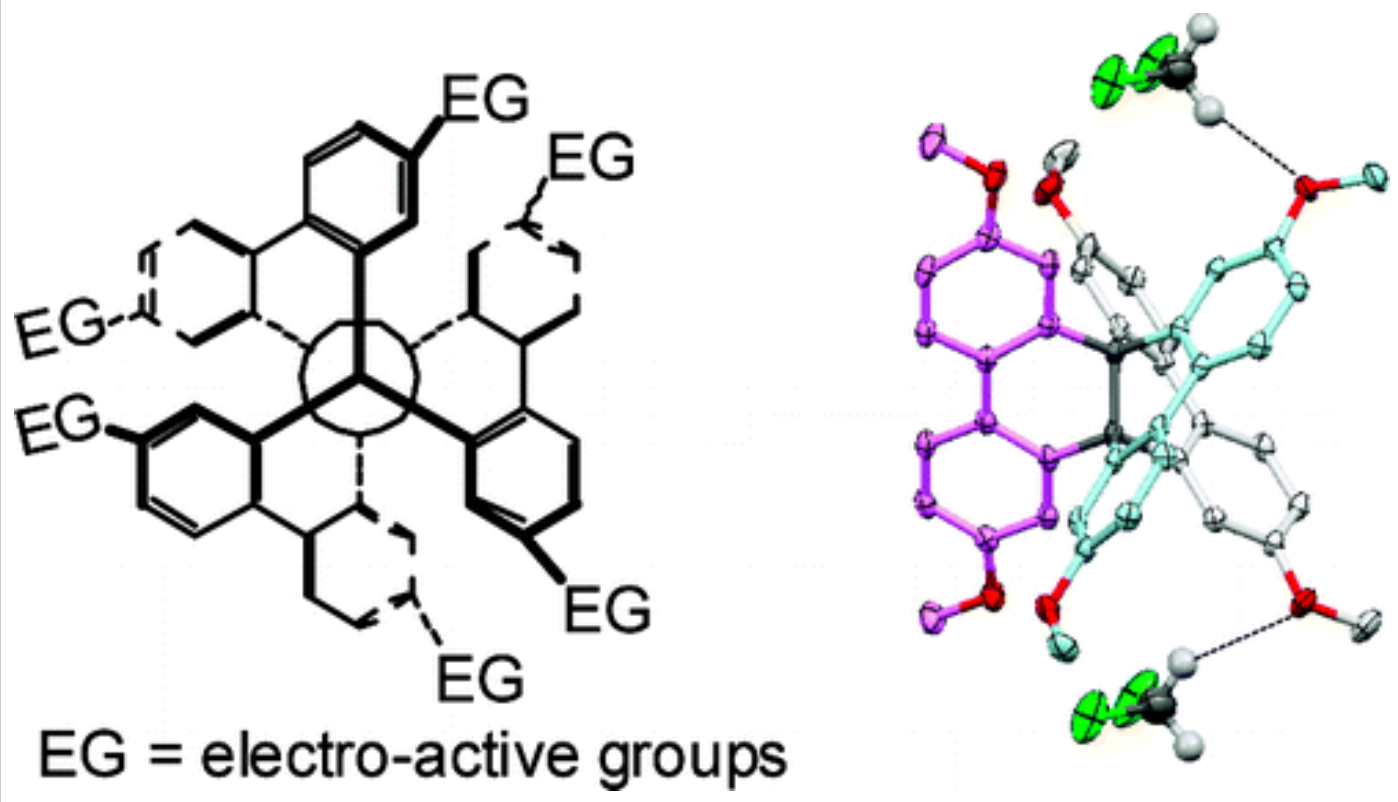

Helical hexabenzo[4.4.4]propellane (a relative of hexaphenylethane) and its derivatives are synthesized and their structures are established by X-ray crystallography. Isolation and X-ray crystallographic characterization of a robust trication-radical salt of hexamethoxypropellane derivative confirms that its framework is stable toward oxidative (aliphatic) $\mathrm{C}-\mathrm{C}$ bond cleavage. It is also demonstrated that propellane can be easily brominated at the $4,4^{\prime}$-positions of the biphenyl linkages for its usage as a molecular platform for the preparation of electroactive materials.

Hexabenzo[4.4.4] propellane $^{1}$ is a relative of hexaphenylethane (HPE) in which the phenyls of HPE from the opposite carbons are linked at the ortho positions to form biphenyl linkages (see structure $A$, Figure 1). Interestingly, unlike hexaphenylethane (HPE) which is yet to be isolated due to its significantly lengthened and consequently weakened central C-C bond, ${ }^{2}$ hexabenzo[4.4.4]propellane (referred to hereafter as propellane) is shown to be completely inert toward the reductive (aliphatic) $\mathrm{C}-\mathrm{C}$ bond cleavage despite its close structural resemblance to the parent HPE. ${ }^{1}$<smiles>c1ccc(CC(c2ccccc2)C(CC(c2ccccc2)C2c3ccccc3C2c2ccccc2)c2ccccc2)cc1</smiles>

HPE

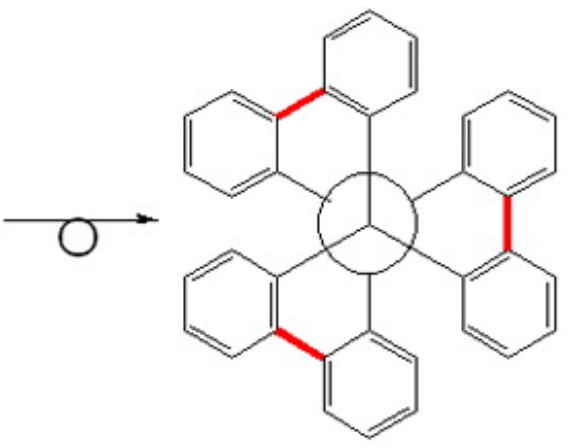

Structure A

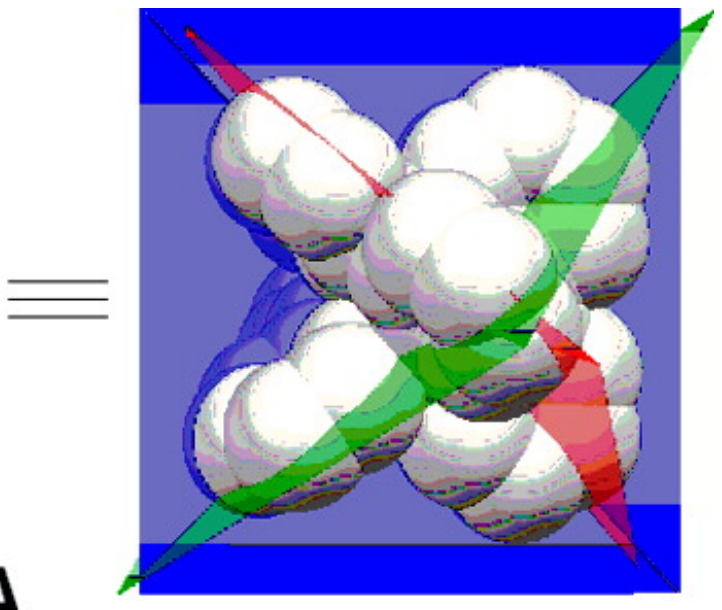

Figure 1 Orthogonal helical arrangement of the biphenyl moieties in parent propellane. 
Density functional theory (DFT) calculations at B3LYP/6-31G* level showed that the molecular geometry of propellane $\left(D_{3 h}\right)$ features three biphenyl moieties lying orthogonal to each other in a helical arrangement at an aliphatic $\mathrm{C}-\mathrm{C}$ bond (i.e., Figure 1$).^{3}$

It was conjectured that propellane may serve as a next-generation molecular platform containing three orthogonally juxtaposed and readily functionalizable biphenyl linkages (Figure 2) for the preparation of electroactive materials for the applications in the emerging areas of molecular electronics and nanotechnology. ${ }^{4}$ In this context, it is important to note that spiro-bifluorene is extensively utilized as a platform for the preparation of molecular wires that lie orthogonal to each other at an insulating juncture, ${ }^{5}$ i.e., Figure 2.

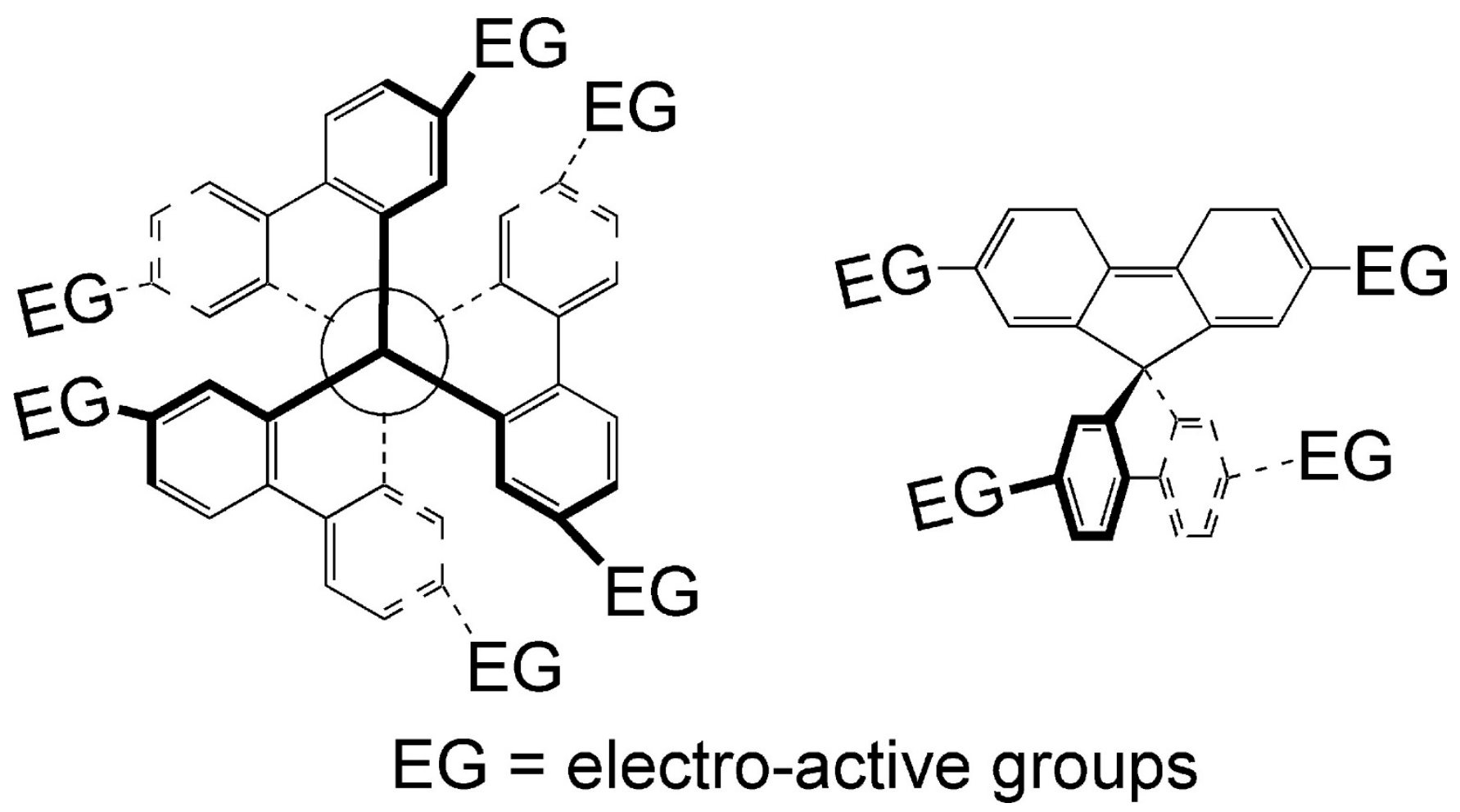

Figure 2 Comparison of (helical) propellane and spiro-bifluorene platforms for designing electroactive materials.

Before undertaking the exploration of propellane and its derivatives for the preparation of electroactive materials, one needs to establish (i) that it is stable toward both reductive as well as oxidative cleavage of the central $\mathrm{C}-\mathrm{C}$ bond and (ii) to demonstrate that it can be readily functionalized at the 4,4'-positions, i.e., Figure 2.

Accordingly, herein we present, for the first time, the structures of propellane and its derivatives by Xray crystallography and establish that they are stable toward oxidative degradation by the isolation and $X$-ray crystallographic characterization of a stable tri-cation-radical salt of an electron-rich propellane. Furthermore, we will show that the parent propellane can be easily brominated at the 4,4'-positions of all three biphenyls for attachment of various electroactive groups using standard palladium-catalyzed coupling reactions. 
Thus, parent propellane 3 (or structure A) was obtained in $\sim 60 \%$ overall yield by a reaction of 2biphenyllithium with readily available pinacolone $\mathbf{1}$ (derived from fluorenone) ${ }^{6}$ followed by an acidcatalyzed Wagner-Meerwein rearrangement/cyclization of the resulting carbinol 2 (Scheme 1) using a slightly modified procedure of Wittig. ${ }^{1}$ A similar reaction with easily available 4,4'-di-tert-butyl-2biphenyllithium ${ }^{7}$ similarly afforded di-tert-butylated derivative $\mathbf{5}$ in $\mathbf{7 5 \%}$ yield. It is noteworthy that 5 can be easily and quantitatively de-tert-butylated to produce 3 by a reaction of 5 in benzene with $\mathrm{AlCl}_{3}-\mathrm{CH}_{3} \mathrm{NO}_{2}$ as a catalyst ${ }^{7}$ (Scheme 1). Moreover, both 3 and 5 can be fully tert-butylated at the 4,4'positions by reaction with tert-butyl chloride in dichloromethane using ferric chloride as a catalyst $^{8}$ (Scheme 1).

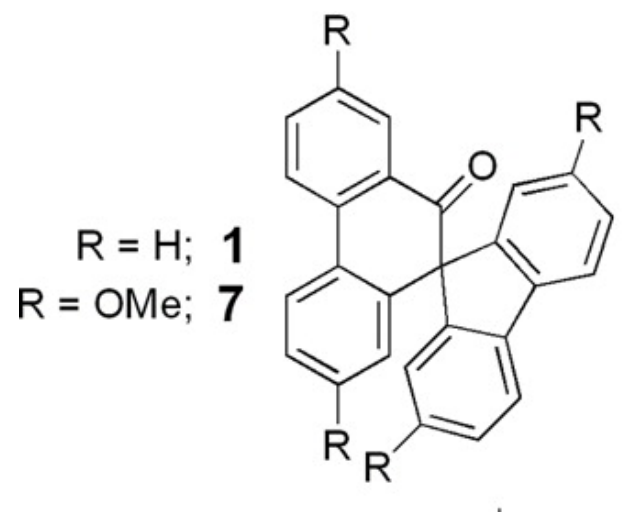<smiles>[R]c1ccc(-c2ccc([R])cc2[Tl])cc1</smiles><smiles>[R]c1ccc(-c2ccc([R])cc2C2(O)c3cc([R])ccc3-c3ccc([R])cc3C23c2cc([R])ccc2-c2ccc([R])cc23)cc1</smiles>

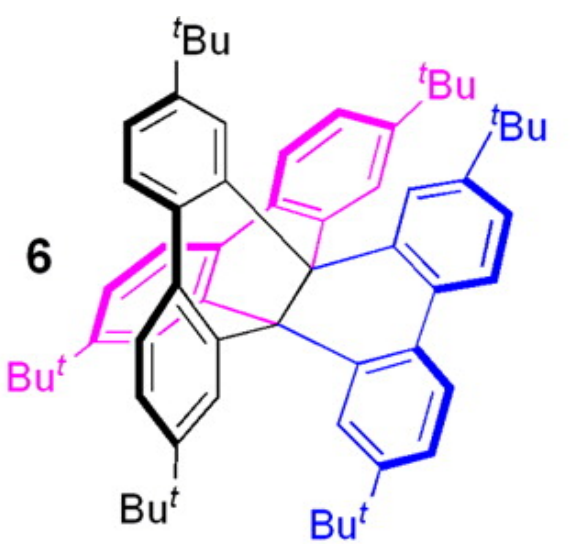

$$
\begin{array}{r}
R=H, R^{\prime}=H ; 2 \\
R=H, R^{\prime}={ }^{t} B u ; 4 \\
R, R^{\prime}=\text { OMe; } 8
\end{array}
$$

$$
\begin{gathered}
\mathrm{R}=\mathrm{H}, \mathrm{R}^{\prime}=\mathrm{H} ; \mathbf{3} \\
\mathrm{R}=\mathrm{H}, \mathrm{R}^{\prime}={ }^{\mathrm{t} B u} ; \mathbf{5} \\
\mathrm{R}, \mathrm{R}^{\prime}=\mathrm{OMe} ; \mathbf{9}
\end{gathered} \quad \begin{gathered}
\mathrm{AlCl}_{3} \\
\mathrm{Benzene}^{\mathrm{CH}} \mathrm{CHO}_{2}
\end{gathered}
$$

Scheme 1. Preparation of Propellane and Its Derivatives

An electron-rich propellane derivative containing methoxy groups at the 4,4'-positions was also obtained using a similar strategy as summarized in Scheme 1. Thus, 2,7-dimethoxy-9-fluorenone ${ }^{9}$ was subjected to reductive coupling using $\mathrm{Zn} / \mathrm{ZnCl}_{2}$ in $\mathrm{THF}-\mathrm{H}_{2} \mathrm{O}$ followed by an acid-catalyzed 
rearrangement of the resulting pinacol to the corresponding pinacolone $\mathbf{7}$ in nearly quantitative yield (Scheme 1). A reaction of 7 with 4,4'-dimethoxy-2-biphenyllithium ${ }^{10}$ in anhydrous ether followed by acid-catalyzed rearrangement/cyclization of the corresponding carbinol 8 afforded propellane $\mathbf{9}$ in $53 \%$ isolated yield.

The molecular structures of $3,5,6$, and 9 were established with the aid of ${ }^{1} \mathrm{H} /{ }^{13} \mathrm{C}$ NMR spectroscopy (see the Supporting Information) and were further confirmed by X-ray crystallography as follows.

The determination of precise molecular structures of various propellanes by X-ray crystallography (see Figure 3 for a representative structure) established that the central (aliphatic) $\mathrm{C}-\mathrm{C}$ bond is only slightly

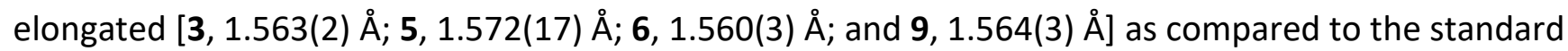
value of $1.530 \AA$ for a $C\left(s p^{3}\right)-C\left(s p^{3}\right)$ bond. ${ }^{11}$ It is also noted that the central $\mathrm{C}-\mathrm{C}$ bonds in various propellanes are relatively shorter than the average value of $1.588 \AA$ for the $\mathrm{C}-\mathrm{C}$ bonds between two tertiary carbons. ${ }^{11}$ The observation of relatively normal $\mathrm{C}-\mathrm{C}$ bond length in various propellanes as compared to the calculated C-C bond length of $1.72 \AA$ for hexaphenylethane ${ }^{2}$ is easily reconciled by the fact that phenyl groups (due to the linkage at ortho-carbons) lie almost in (non-hindered) staggered arrangement along the central $\mathrm{C}-\mathrm{C}$ bond, i.e., the average dihedral angles $\phi(\mathrm{Ph}-\mathrm{C}-\mathrm{C}-\mathrm{Ph})$ are close to the ideal $60^{\circ}$ value. (For a complete listing of important bond lengths, angles, and dihedral angles of various X-ray structures reported herein, see Table S1 in the Supporting Information).
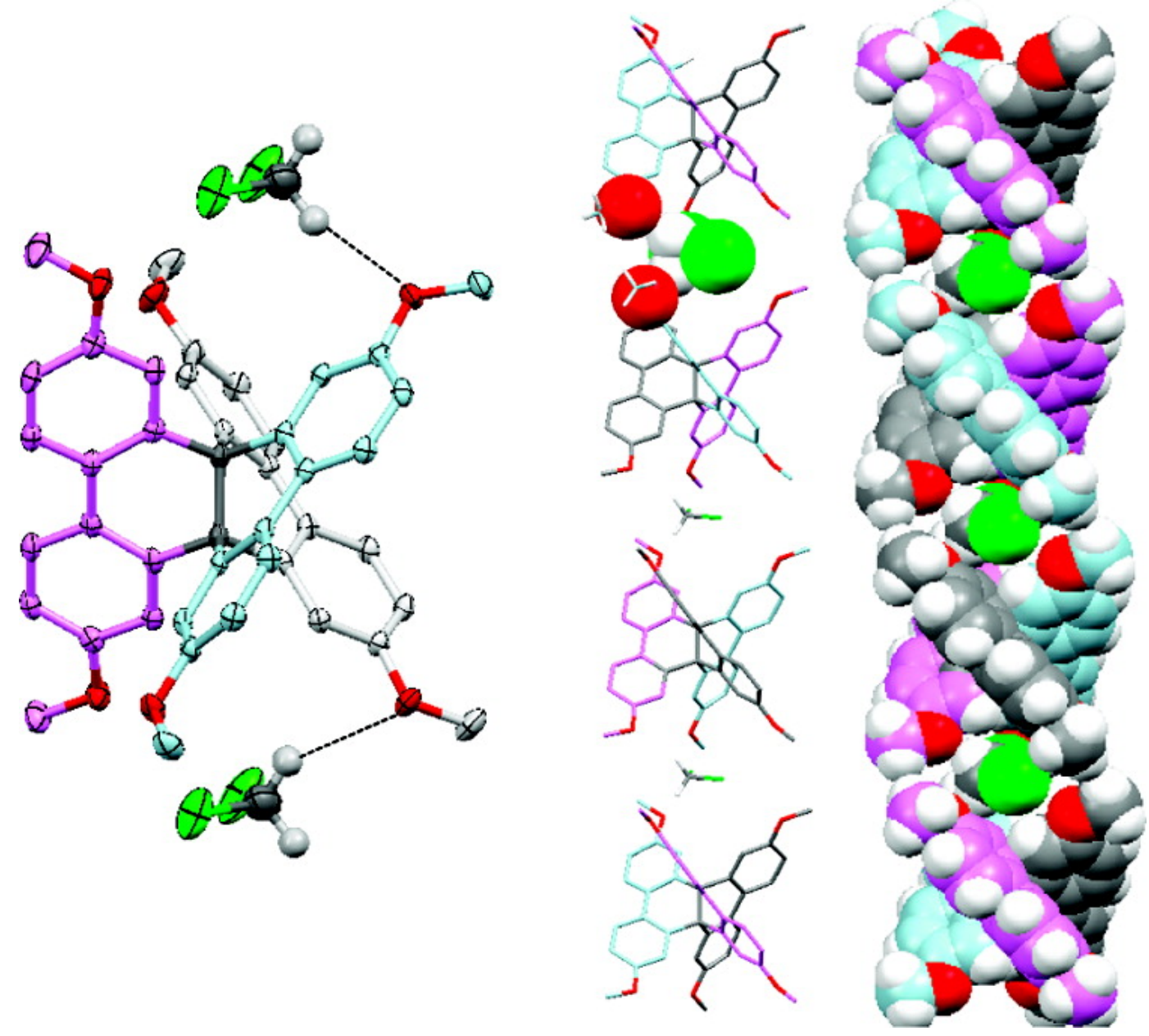

Figure 3 ORTEP diagram of $\left[9 \cdot \mathrm{CH}_{2} \mathrm{Cl}_{2}\right]$ and its triple helical packing arrangement. 
Despite the inherent helicity (chirality) of the propellane framework and a very high barrier of racemization, the synthesis described in Scheme 1 produces only the racemic mixtures of various propellanes (i.e., 3, 5, 6, and 9). Expectedly, the crystallizations of the racemic 3, 5, and $\mathbf{6}$ yield the crystals containing closely packed stacks of molecules of alternating chirality. Interestingly, however, hexamethoxypropellane $\mathbf{9}$ forms triple helical columns by stacking molecules of one enantiomer onto each other (see Figure 3). The molecules of 9 in the helix are linked together via an alternating dichloromethane molecule by $\mathrm{C}-\mathrm{H} \cdots \mathrm{O}$ contacts with the distance and angle of $2.63 \AA$ and $139^{\circ}$, respectively (see Figure 3 ). Note that "helixes" of alternating chirality (formed from the enantiomers of 9) pack adjacent to each other in the crystal with multiple contacts. As such, this observation suggests that propellane framework may represent an interesting building block for devising supramolecular helical arrays for interesting nonlinear optoelectronic properties and electrical conductivity. ${ }^{12}$

With the various propellane derivatives at hand, we next evaluated their electron-donor strength and the initial indication of the oxidative stability by cyclic voltammetry.

Thus, each propellane was subjected to electro-chemical oxidation at a platinum electrode as a $2 \mathrm{mM}$ solution in dichloromethane containing $0.1 \mathrm{Mn}-\mathrm{Bu}_{4} \mathrm{NPF}_{6}$ as the supporting electrolyte. Figure $4 \mathrm{~A}$ shows the cyclic voltammograms of $\mathbf{9}$ with three reversible 1-electron oxidations occurring at the potentials of $1.17,1.37$, and $1.51 \mathrm{~V}$ vs SCE for the formation of mono-, di-, and trication radical, respectively. ${ }^{13}$ Similarly, tert-butylated derivatives $\mathbf{5}$ and $\mathbf{6}$ also showed reversible waves for the first oxidation at a potential of 1.60 and $1.55 \mathrm{~V}$ vs SCE, while the later oxidations occurring at relatively higher potentials with irreversible waves (see Figures S1 and S2 in the Supporting Information). The reversibility of electrochemical oxidations of 5,6 , and $\mathbf{9}$ indicates that the central $\mathrm{C}-\mathrm{C}$ bond in these molecules do not undergo oxidative cleavage at least on the electrochemical time-scale. ${ }^{14}$
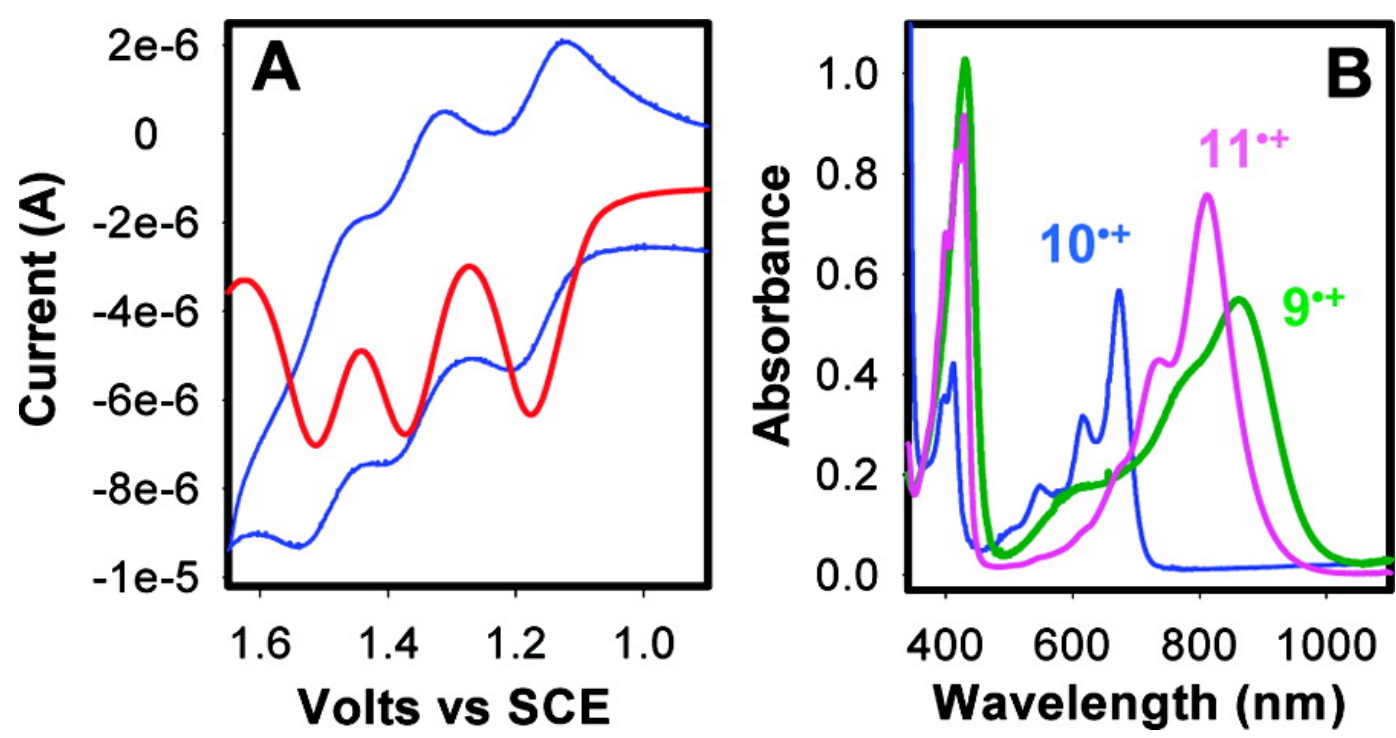

Figure 4 (A) Cyclic and square-wave voltammograms of $2 \times 10^{-3} \mathrm{M} 9$ in $\mathrm{CH}_{2} \mathrm{Cl}_{2}\left(0.1 \mathrm{M} \mathrm{n}\right.$ - $\left.\mathrm{Bu}_{4} \mathrm{NPF}_{6}\right)$ at a scan rate $200 \mathrm{mVs}^{-1}$. (B) Comparison of the UV-vis absorption spectra of cation radicals of 9 (green) and dimethoxybiphenyl 11 (pink), obtained using $\mathbf{1 0}^{+\bullet}$ (blue) as an oxidant in $\mathrm{CH}_{2} \mathrm{Cl}_{2}$ at $22^{\circ} \mathrm{C}$. 
The electrochemical reversibility and relatively low oxidation potential of 9 prompted us to carry out its oxidation to the corresponding cation radical using a stable naphthalene cation radical $\left(\mathbf{1 0}^{\mathbf{*}}\right)^{15}$ as an aromatic one-electron oxidant $\left(E_{\mathrm{ox}}=1.34 \mathrm{~V}\right.$ vs SCE).

Thus, Figure 4B shows the spectrum of $9^{\bullet+}$ obtained by a reaction of a $6.1 \times 10^{-5} \mathrm{M}$ solution of $10^{\circ+}\left(\lambda_{\max }=672,616,503 \text {, and } 396 \mathrm{~nm} ; \varepsilon_{672}=9300 \mathrm{M}^{-1} \mathrm{~cm}^{-1}\right)^{15}$ with 1 equiv of 9 in dichloromethane at $22{ }^{\circ} \mathrm{C}$, i.e., eq 1 .

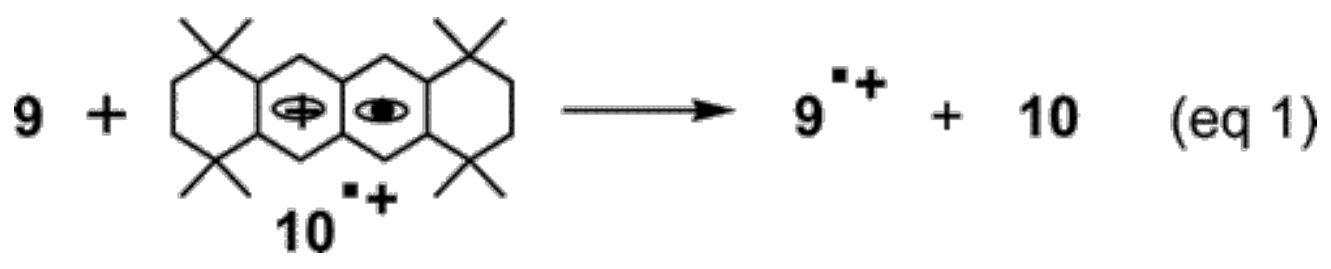

The characteristic absorption spectrum of green-colored $9^{\circ+}$ with a structured absorption band $\left(\lambda_{\max }=\right.$ $430,861 \mathrm{~nm})$ was expectedly similar to that of the 4,4'-dimethoxybiphenyl (11) cation radical ${ }^{16}\left(\lambda_{\max }=\right.$ $428,812 \mathrm{~nm}$ ), i.e. Figure 4B. (For complete details for the generation of cation radicals of 9 and 11, see Supporting Information.)

It is noteworthy that the green-colored $\mathbf{9}^{\bullet+}$, obtained in eq 1 , is highly persistent at ambient temperatures and did not show any decomposition during a $12 \mathrm{~h}$ period at $22{ }^{\circ} \mathrm{C}$ as confirmed by UV-vis spectroscopy. It is to be further noted that the reduction of $9^{\circ+}$ with zinc dust regenerated the neutral 9 quantitatively, as confirmed by ${ }^{1} \mathrm{H} /{ }^{13} \mathrm{C}$ NMR spectroscopy. The high stability of the $9^{\bullet+}$ lends support to the fact that propellane derivatives are stable toward oxidative $\mathrm{C}-\mathrm{C}$ bond cleavage, and thus, we next attempted the isolation of crystalline $9^{\bullet+}$ as follows.

Treatment of a solution of 9 with triethyloxonium hexachloroantimonate $\left(\mathrm{Et}_{3} \mathrm{O}^{+} \mathrm{SbCl}_{6}{ }^{-}\right)$- an efficient $1 \mathrm{e}^{-}$oxidant for the isolation of crystalline cation-radical salts ${ }^{17}$ - in dichloromethane at $\sim 0{ }^{\circ} \mathrm{C}$ immediately resulted in a dark-green solution which was spectrally identical to that obtained above as in eq 1 . The green-colored solution was carefully layered with toluene and stored in a refrigerator at $-10{ }^{\circ} \mathrm{C}$ for 2 days. The crystallographic analysis of the dark-colored crystals thus obtained, indicated that the crystals consisted of a tri-cation-radical salt $\left[9^{3 \cdot+} 3 \mathrm{SbCl}_{6}^{-}\right]$, most likely formed by crystallization induced disproportionation $\left[9^{\bullet+} \mathrm{SbCl}_{6}^{-}\right] .{ }^{18}$

Figure 5 shows that the crystal structure of $\left[9^{3 \cdot+} 3 \mathrm{SbCl}_{6}^{-}\right]$consists of columns of tricationic $9^{3 \cdot+}$ with alternating chirality as opposed to neutral $\mathbf{9}$ (vide supra) along one axis surrounded by 4 equiv of toluene molecules (two of them are rotationally disordered within molecular plane) and separated by layers containing 3 equiv of $\mathrm{SbCl}_{6}^{-}$(two in general positions and two halves on 2-fold axes) and several heavily disordered solvent molecules. The columns of $\mathbf{9}^{\mathbf{3}+}$ are built on a 6 -fold $0 \cdots$ Ar contacts (as close as $3.05 \AA$ ) which may correspond to attractive interactions between the dipoles of the methoxy groups with delocalized positive charge on the aromatic moieties. Unfortunately, the low experimental precision severely limits discussion of the bond-length changes in $9^{3 \cdot+}$, but the averaged bond lengths are in a good agreement with the expected quinoidal distortion of dimethoxybiphenyl moieties (see Table S1 in the Supporting Information). 


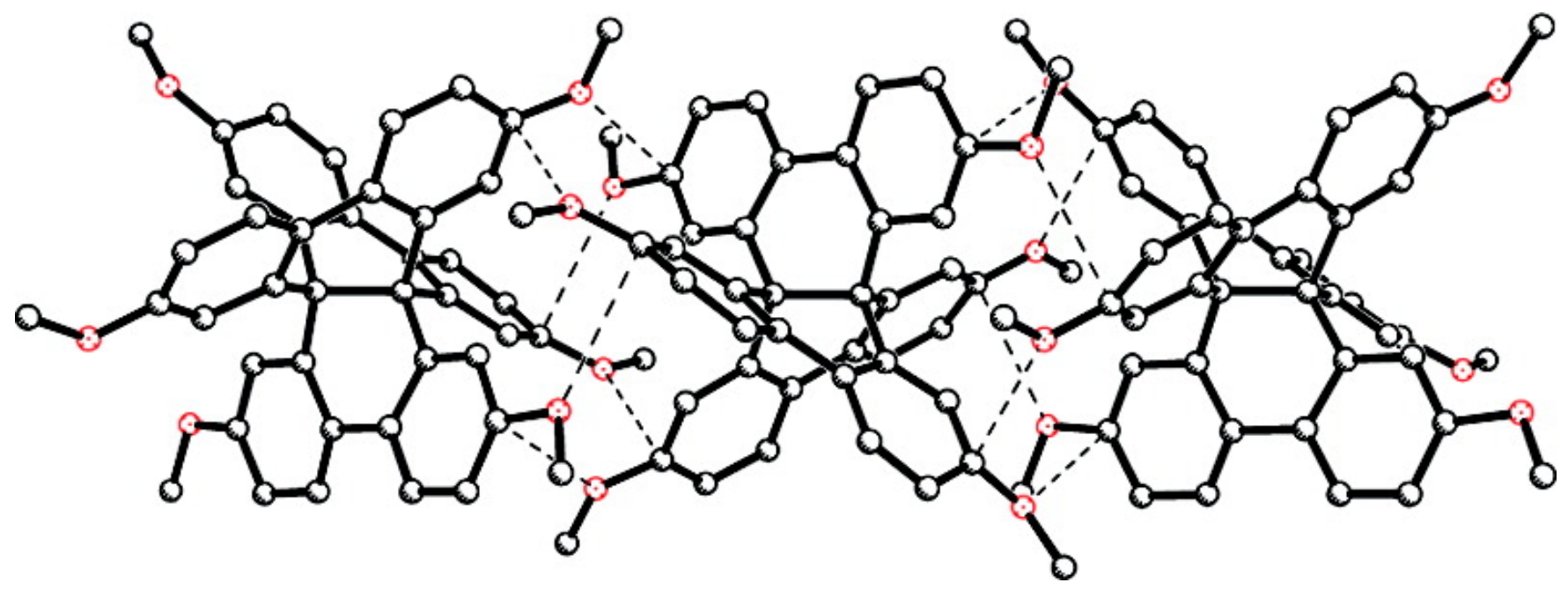

Figure 5 Packing arrangement of racemic tricationic 9 with multiple $0 \cdots$ Ar contacts.

It is also noted that reduction of $\mathbf{9}^{3 \bullet+}$ using $\mathbf{Z n}$ dust or borane-dimethyl sulfide complex ${ }^{19}$ regenerated the neutral $\mathbf{9}$ in quantitative yield and thereby further attesting to the stability of the central $\mathrm{C}-\mathrm{C}$ bond in propellanes toward oxidative cleavages.

Having established that propellanes are stable toward both reductive ${ }^{1}$ and oxidative cleavage of the central C-C bond, we next explored if they can be functionalized at the 4,4'-postions of three orthogonal biphenyl moieties (see Figure 2) for the preparation of electro-active materials as follows.

Thus, parent propellane $\mathbf{3}$ was subjected to a bromination reaction in dichloromethane in the presence of powdered iron as a catalyst for $4 \mathrm{~h}$ to afford $\mathbf{1 2}$ in quantitative yield with selectivebromination at 4,4'-positions as established by X-ray crystallography (see Scheme 2). Moreover, hexabromopropellane 12 underwent efficient Suzuki coupling reactions with 2,5dimethoxytolylboronic acid and 9,9-dihexyl-2-fluoreneboronic acid, under standard conditions, to afford arylated derivatives $\mathbf{1 3}$ and $\mathbf{1 4}$ in excellent yields (see Scheme 2). 

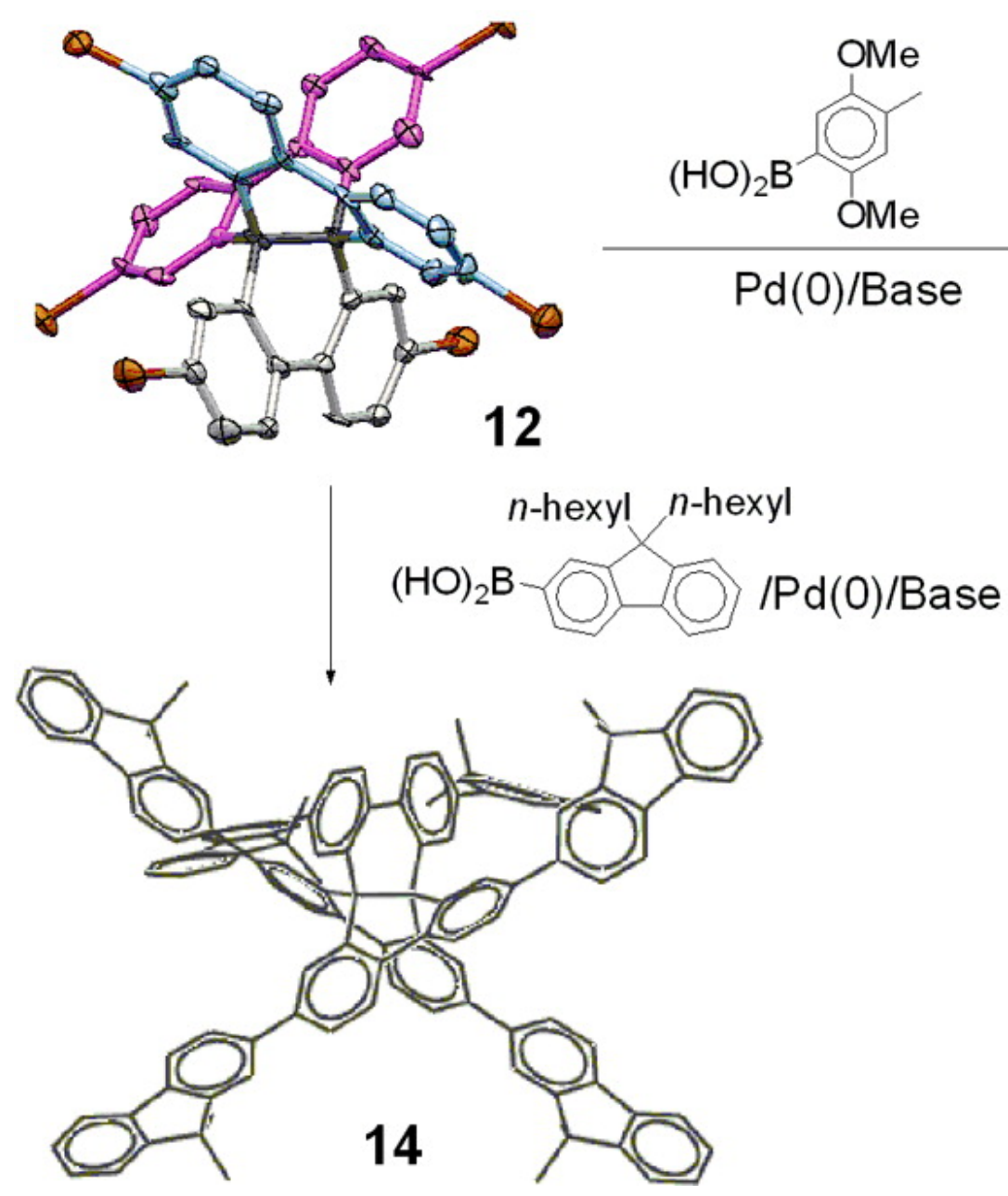

Scheme 2. Preparation of Electroactive Propellanes

In summary, we have synthesized and established structures of propellane and its derivatives by $\mathrm{X}$-ray crystallography. The helical propellane framework is stable toward both reductive and oxidative $\mathrm{C}-\mathrm{C}$ bond cleavage as shown by isolation and X-ray crystallographic characterization of a stable tricationradical salt. Moreover, parent propellane $\mathbf{3}$ can be easily transformed to the hexabromopropellane $\mathbf{1 2}$ which in turn was utilized for the preparation of electroactive derivatives 13 and 14 (Scheme 2). These findings demonstrate that the propellane framework can serve as a platform for the preparation of futuristic electroactive materials for practical applications.

\section{Acknowledgment}

We thank the National Science Foundation (CAREER Award) for financial support.

\section{References}

1Wittig, G.; Schoch, W. J. Liebigs Ann. Chem. 1971, 749, 38. Also see: Kimura, M.; Kuwano, S.; Shimada, K.; Kamata, R.; Yasuda, S.; Sawaki, Y.; Fujikawa, H.; Noda, K.; Taga, Y.; Takagi, K. Bull. Chem. Soc. Jpn.2006, 79, 1793.

2(a) Vreven, T.; Morokuma, K. J. Phys. Chem. A 2002, 106, 6167. (b) Yannoni, N.; Kahr, B.; Mislow, K. J. Am. Chem. Soc. 1988, 110, 6670 and references therein. 
3Note that propellane possesses geometric similarity to the metal-tris-bipyridyls in which three bipyridyl moieties lie almost orthogonally around the octahedral metal center.

4(a) Introduction to Molecular Electronics; Petty, M. C., Bryce, M. R., Bloor, D., Eds.; Oxford University Press: New York, 1995. (b) Maiya, B. G.; Ramasarma, T. Curr. Sci. 2001, 80, 1523.

5(a) Tour, J. M. Chem. Rev. 1996, 96, 537. (b) Wu, R.; Schumm, J. S.; Pearson, D. L.; Tour, J. M. J. Org. Chem. 1996, 61, 6906. (c) Wu, Y.; Li, J.; Fu, Y.; Bo, Z. Org. Lett. 2004, 6, 3485 and references therein.

6Hoang, M.; Gadosy, T.; Ghazi, H.; Hou, D.-F.; Hopkinson, A. C.; Johnston, L. J.; Lee-Ruff, E. J. Org. Chem.1998, 63, 7168.

7Tashiro, M.; Yamato, T. J. Org. Chem. 1979, 44, 3037.

8Rathore, R.; Burns, C. L. J. Org. Chem. 2003, 68, 4071.

9Epperson, J. R.; Bruce, M. A.; Catt, J. D.; Deskus, J. A.; Hodges, D. B.; Karageorge, G. N.; Keavy, D. J.; Mahle, C. D.; Mattson, R. J.; Ortiz, A. A.; Parker, M. F.; Takaki, K. S.; Watson, B. T.; Yevich, J. P. Bioorg. Med. Chem. 2004, 12, 4601.

10Sparling, J.; Fung, D.; Safe, S. Biomed. Mass Spectrom. 1980, 7, 13.

11Cambridge Structural Database (CSD).

12Compare: Rajca, A.; Safronov, A.; Rajca, S.; Shoemaker, R. Angew. Chem., Int. Ed. Engl. 1997, 36, 488.

13There is little or no possibility of "through-space" interaction between the cationic biphenyl moieties in propellanes due to their orthogonal juxtapostion with respect to each other. Thus, splitting of the oxidation waves in $\mathbf{9}$ most likely arises due to the Coulombic repulsion amongst the orthogonally juxtaposed cationic biphenyls.

14The parent propellane (3) showed only an irreversible oxidation wave at $\sim 1.8 \mathrm{~V}$. Such an observation does not necessarily imply the instability of the resulting cation radical towards $\mathrm{C}-\mathrm{C}$ bond cleavage but most likely indicates its high electrophilic reactivity similar to that observed for the unsubstituted biphenyl cation radical.

15Rathore, R.; Le Mague'res, P.; Lindeman, S. V.; Kochi, J. K. Angew. Chem., Int. Ed. 2000, 39, 809.

16Singular absence of any additional absorption bands (in near IR region) in hexamethoxypropellane cation radical when compared to 4,4'-dimethoxybiphenyl cation radical suggests the lack of electronic coupling amongst the orthogonally juxtaposed biaryl moieties in propellanes. ${ }^{13}$

17Rathore, R.; Kumar, A. S.; Lindeman, S. V.; Kochi, J. K. J. Org. Chem. 1998, 63, 5847.

18Compare: Rathore, R.; Lindeman, S. V.; Kumar, A. S.; Kochi, J. K. J. Am. Chem. Soc. 1998, 120, 6931. 19Rathore, R.; Burns, C. L.; Guzei, I. A. J. Org. Chem. 2004, 69, 1524. 